\title{
The Shift of the Ischial Region during Maneuvering the Standard Wheelchair and the Electric Wheelchair in Healthy Adults
}

\author{
Mikiko Uemura1,2*, Masaharu Sugimoto ${ }^{3}$, Ryoko Shimizu4, Noriaki Maeshige2, \\ Yoshiyuki Yoshikawa ${ }^{5}$, Hidemi Fujino² \\ ${ }^{1}$ Faculty of Health Science, Department of Rehabilitation, Kansai University of Welfare Sciences, Kashiwara, Japan \\ ${ }^{2}$ Department of Rehabilitation Science, Graduate School of Health Sciences, Kobe University, Kobe, Japan \\ ${ }^{3}$ Toyama Rehabilitation Medical Health and Welfare College, Toyama, Japan \\ ${ }^{4}$ Department of Rehabilitation, Kansai Medical University Hospital, Hirakata, Japan \\ ${ }^{5}$ Faculty of Health Sciences, Department of Rehabilitation, Naragakuen University, Nara, Japan \\ Email: *uemura@tamateyama.ac.jp
}

How to cite this paper: Uemura, M., Sugimoto, M., Shimizu, R., Maeshige, N., Yoshikawa, Y. and Fujino, H. (2021) The Shift of the Ischial Region during Maneuvering the Standard Wheelchair and the Electric Wheelchair in Healthy Adults. International Journal of Clinical Medicine, 12, 297-305. https://doi.org/10.4236/ijcm.2021.127026

Received: June 28, 2021

Accepted: July 23, 2021

Published: July 26, 2021

Copyright $\odot 2021$ by author(s) and Scientific Research Publishing Inc. This work is licensed under the Creative Commons Attribution International License (CC BY 4.0).

http://creativecommons.org/licenses/by/4.0/ (c) (i) Open Access

\begin{abstract}
Pressure injuries are frequent secondary complications that occur in patients with Spinal Cord Injury (SCI), and the recurrence rate of ischial pressure injury is highest in SCI patients. Most SCI patients use wheelchairs, and some studies have shown a relationship between buttock pressure and sitting posture. However, the pressure distribution during wheelchair maneuvering is unclear. We measured and compared the shift of the ischial region when maneuvering a standard wheelchair or electric wheelchair in healthy adults. The subjects drove wheelchairs on a flat ground of $10 \mathrm{~m}$ and the shift of ischial region was measured with a pressure distribution-measuring device. The ischial region shifted forward or backward while maneuvering both the standard wheelchair and the electric wheelchair, and the shift rate of the ischial region was not significantly different between the standard wheelchair and the electric wheelchair. The ischial region shift occurred when the forward head moved by the video while maneuvering both a standard wheelchair and an electric wheelchair. Therefore, the shift might occurred because the pelvis shifted forward in conjunction with head movement during maneuvering of both the standard wheelchair and the electric wheelchair. This result showed that it is important to reduce head and trunk movements when maneuvering a wheelchair to reduce the shear force on the buttocks and prevent pressure injuries.
\end{abstract}

\section{Keywords}

Spinal Cord Injury, Pressure Ulcer, Wheelchair, Buttock Pressure 


\section{Introduction}

Pressure injuries are caused by pressure and shear forces. The activity level of Spinal Cord Injury (SCI) patients who maneuver a wheelchair by themselves is high, and they can drive a car, carry out work, etc. [1]. SCI patients have pathologically protruding bone due to muscle atrophy of the buttocks and joint contracture, which are risk factors for pressure injury development [2]. Pressure injury frequently occurs particularly on the sacral area, ischial area, and the heel in SCI patients [3], and the postoperative recurrence rate was $27 \%$ [4]. Moreover, Jensen reported that the recurrence rate of ischial pressure injury was highest at $53 \%$ compared to that of the other site [5]. The ischial pressure injury often undergoes flap surgery but this surgical treatment needs 2 weeks-bed rest [6], and bed rest induces disuse syndrome such as autonomic disorder and muscle atrophy. Thus, it is crucial to prevent ischial pressure injury development and recurrence. Therefore, some studies have compared the seating pressure distribution effects of seating cushions [7] [8] and the effects of back support and the reclining wheelchair angle on buttock pressure [9] [10] [11] to prevent ischial and sacral pressure injuries. However, these studies assessed buttock pressure in a sedentary sitting posture, and the pressure distribution during wheelchair maneuvering is unclear. As mentioned above, pressure and shear forces cause pressure injuries. The shear force and pressure may occur on the ischial area when the wheelchair cause maneuvers because the trunk and pelvis move during maneuvering.

Therefore, we revealed the shear stress on the ischial site while maneuvering the standard type of wheelchair and electric wheelchair.

\section{Subjects and Methods}

The subjects were 20 healthy adults (10 men and 10 women). Height, weight, Body Mass Index (BMI), and upper limb length were measured. Those with a BMI of $25 \mathrm{~kg} / \mathrm{m}^{2}$ or more were excluded, and 19 subjects (10 males and 9 females) were measured, and all subjects were right-handed.

The change in the maximum pressure section during maneuvering of the wheelchair was measured. A pressure distribution-measuring device (FSA; Force Sensitive Applications, Takano, Japan) was used to measure the sitting pressure. It consists of a $533 \mathrm{~mm}^{2}$, pressure measure seat including $16 \times 16$ pressure sensor (1 piece $25.4 \mathrm{~mm}$, center spacing $3.1 \mathrm{~mm}$ ), data conversion interface module, wireless kit, and Personal Computer (PC). A standard wheelchair was used as a self-propelled wheelchair in the experiment. The electric wheelchair used was JW Active (Yamaha Motor, Japan). Two standard wheelchairs of different seat widths were used according to the physique of the subject. An electric wheelchair joystick was installed on the right armrest. The footrest for both self-propelled and electric was adjusted so that the height of the footrest was $5 \mathrm{~cm}$ or more from the floor. The FSA seat was laid along the front edge of the wheelchair seat. The FSA sampling interval was set at $5 \mathrm{~Hz}$. The subjects wore seamless shorts. In this ex- 
periment, to clarify the position of the ischial region, aluminum plates with a length of $4 \mathrm{~cm}$ and a width of $2 \mathrm{~cm}$ were attached to both sciatic regions of the subject, and a dressing material (Tegasorb ${ }^{\text {TM }}$ hydrocolloid dressing, $3 \mathrm{M}$ Healthcare) was attached for sensor protection. This was confirmed by using a friction reduction tool (multi-glove, paramount bed) to determine whether there was any discrepancy between the actual position of the ischial region and the position displayed using the device.

For the driving method, a certain method was set so that there would be no difference due to driving. For self-propelled wheelchairs, the apex of the hand rim was set to $0^{\circ}$. Instructions were given to drive in the range of $30^{\circ}$ to $60^{\circ}$ forward, and the number of drives was set to once per second according to the metronome. The electric wheelchair was set to $3.8 \mathrm{~km} / \mathrm{h}$ and the subjects were instructed to move only their right hand. After practicing the driving method for both the standard wheelchair and the electric wheelchair, the pressure on the ischial region was measured by driving on a flat ground of $10 \mathrm{~m}$ three times each. The movement of the body during driving was recorded from the side using a PC equipped with a camera.

A chi-square test was used for statistical analysis, and the risk rate was set to less than $5 \%$ in each case.

\section{Results}

The characteristics of the participants are listed in Table 1. The average driving time of a self-propelled wheelchair was $10.1 \pm 1.4$ seconds for men and $10.7 \pm 2.1$ seconds for women, the average number of driving times was $10.0 \pm 1.3$ times for men and $10.6 \pm 2.0$ times for women, and the average driving speed was 3.63 $\pm 0.51 \mathrm{~m} / \mathrm{s}$ for men and $3.50 \pm 0.62 \mathrm{~m} / \mathrm{s}$ for women. Regarding the presence or absence of ischial displacement, it was judged that the ischial displacement occurred only when the maximum pressure region of the ischial pressure distribution moved anteriorly or posteriorly, and the position of the original maximum pressure region moved in the same direction. The displacement of the ischial region that occurred in this study was a forward sensor. Figure 1 shows an example in which the sitting pressure distribution in the ischial region changed and displacement occurred when driving a self-propelled wheelchair. Figure 1(a) shows the distribution at the moment when the hand rim is pushed forward, Figure 1(b) shows the distribution at the moment when the hand is released from the hand rim, and Figure 1(c) shows the distribution at the moment when the hand rim is gripped again. The area surrounded by a square on the sensor seat was the position of the ischium. A comparison of Figure 1(a) and Figure 1 (b) shows that the maximum pressure region of both ischia moves forward, and when comparing Figure 1(b) and Figure 1(c), the maximum pressure region returns to the rear.

For electric wheelchairs, the moment of the joystick was pushed forward was set as the start of driving. Similar to the self-propelled wheelchair, those who 
showed a change in the maximum pressure region during driving were taken as an example of displacement in the ischial region. In self-propelled wheelchairs, the number of people with ischial displacement was eight for men and three for women, and the displacement detection rates (number of detectors/subjects) were $80 \%$ for men and $33.3 \%$ for women. In electric wheelchairs, the number of people with ischial displacement was three for men and three for women, and the displacement detection rates were 30\% for men and 33.3\% for women. Table 2 and Table 3 show the number of deviation section for each subject, Table 4 shows the number of people who have a deviation in each wheelchair.

No significant association was found in the ischial displacement between the wheelchairs in all subjects. Distinguishing between men and women, a significant association was found between self-propelled wheelchair driving and ischial displacement in men $(p<0.05)$, while no significant association was found in women.
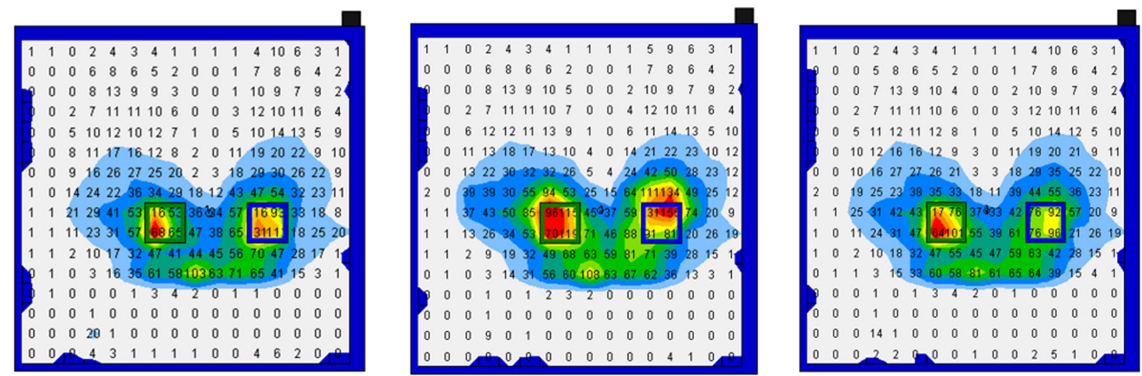

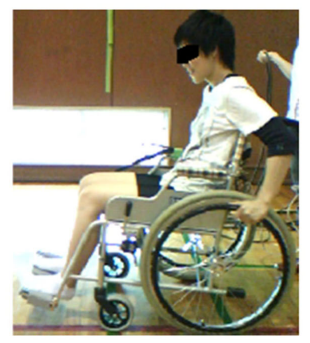

(a)

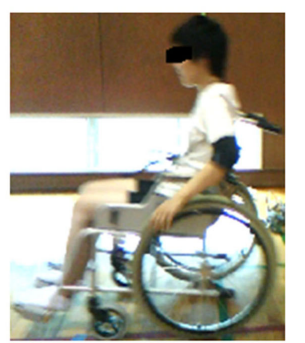

(b)

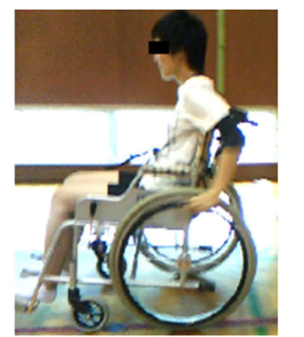

(c)

Figure 1. Sitting pressure distribution in the ischial region. The area surrounded by qualifications means ischial area. (a): The moment that a subject pushed the hand rim forward; (b): The moment that a subject released the hand rim; (c): The moment that a subject griped the hand rim again. Right and left ischial area shifted forward when a subject released the hand $\operatorname{rim}(a, b)$, and the ischial are returned the rear $(b, c)$.

Table 1. Characteristics of subjects.

\begin{tabular}{ccc}
\hline & Male & Female \\
\hline Age (years) & $22 \pm 1.9$ & $21 \pm 0.8$ \\
Height $(\mathrm{cm})$ & $169.2 \pm 3.92$ & $160.1 \pm 5.17$ \\
Wight $(\mathrm{kg})$ & $58.2 \pm 4.42$ & $53.4 \pm 5.66$ \\
BMI $\left(\mathrm{kg} / \mathrm{m}^{2}\right)$ & $20.3 \pm 1.27$ & $20.3 \pm 1.38$ \\
Upper limb length $(\mathrm{cm})$ & $55.5 \pm 1.43$ & $51.8 \pm 2.15$ \\
\hline
\end{tabular}


Table 2. The number of deviation section in male.

\begin{tabular}{ccccccccccccc}
\hline & $\begin{array}{c}\text { Standard } \\
\text { wheelchair } \\
\text { 1st drive }\end{array}$ & \multicolumn{2}{c}{$\begin{array}{c}\text { Standard } \\
\text { wheelchair } \\
\text { 2nd drive }\end{array}$} & \multicolumn{2}{c}{$\begin{array}{c}\text { Standard } \\
\text { wheelchair } \\
\text { 3rd drive }\end{array}$} & \multicolumn{2}{c}{$\begin{array}{c}\text { Electric } \\
\text { wheelchair } \\
\text { 1st drive }\end{array}$} & \multicolumn{2}{c}{$\begin{array}{c}\text { Electric } \\
\text { wheelchair } \\
\text { 2nd drive }\end{array}$} & $\begin{array}{c}\text { Electric } \\
\text { wheelchair } \\
\text { 3rd drive }\end{array}$ \\
\hline Ischial & Left & Right & Left & Right & Left & Right & Left & Right & Left & Right & Left & Right \\
\hline Case A & 1 & 1 & 0 & 1 & 0 & 1 & 0 & 0 & 0 & 0 & 0 & 0 \\
Case B & 1 & 1 & 0 & 1 & 0 & 1 & 0 & 0 & 0 & 0 & 0 & 0 \\
Case C & 0 & 1 & 1 & 1 & 0 & 0 & 0 & 0 & 0 & 0 & 1 & 1 \\
Case D & 0 & 0 & 1 & 1 & 1 & 1 & 1 & 1 & 0 & 0 & 1 & 1 \\
Case E & 0 & 0 & 0 & 0 & 0 & 0 & 0 & 0 & 0 & 0 & 0 & 0 \\
Case F & 1 & 1 & 0 & 0 & 0 & 0 & 0 & 0 & 0 & 0 & 0 & 0 \\
Case G & 0 & 0 & 0 & 0 & 1 & 0 & 0 & 0 & 0 & 0 & 1 \\
Case H & 0 & 0 & 1 & 0 & 0 & 0 & 0 & 0 & 0 & 0 & 0 \\
Case I & 1 & 1 & 0 & 1 & 1 & 1 & 0 & 0 & 0 & 0 & 0 \\
Case J & 0 & 0 & 0 & 0 & 0 & 0 & 0 & 0 & 0 & 0 & 0 \\
\hline
\end{tabular}

Table 3. The number of deviation section in female.

\begin{tabular}{ccccccccccccc}
\hline & $\begin{array}{c}\text { Standard } \\
\text { wheelchair } \\
\text { 1st drive }\end{array}$ & \multicolumn{2}{c}{$\begin{array}{c}\text { Standard } \\
\text { wheelchair } \\
\text { 2nd drive }\end{array}$} & $\begin{array}{c}\text { Standard } \\
\text { wheelchair } \\
\text { 3rd drive }\end{array}$ & $\begin{array}{c}\text { Electric } \\
\text { wheelchair } \\
\text { 1st drive }\end{array}$ & $\begin{array}{c}\text { Electric } \\
\text { wheelchair } \\
\text { 2nd drive }\end{array}$ & $\begin{array}{c}\text { Electric } \\
\text { wheelchair } \\
\text { 3rd drive }\end{array}$ \\
\hline Ischial & Left & Right & Left & Right & Left & Right & Left & Right & Left & Right & Left & Right \\
\hline Case a & 0 & 0 & 0 & 0 & 0 & 0 & 0 & 0 & 0 & 0 & 0 & 0 \\
Case b & 0 & 0 & 0 & 0 & 0 & 0 & 0 & 0 & 1 & 0 & 0 & 0 \\
Case c & 0 & 0 & 0 & 0 & 1 & 0 & 1 & 0 & 0 & 0 & 1 & 1 \\
Case d & 1 & 0 & 1 & 0 & 1 & 0 & 0 & 0 & 0 & 0 & 0 & 0 \\
Case e & 0 & 0 & 0 & 0 & 0 & 0 & 0 & 0 & 0 & 0 & 0 & 0 \\
Case f & 0 & 0 & 0 & 0 & 0 & 0 & 0 & 0 & 0 & 0 & 0 & 0 \\
Case g & 1 & 1 & 1 & 1 & 0 & 0 & 1 & 1 & 0 & 0 & 0 \\
Case h & 0 & 0 & 0 & 0 & 0 & 0 & 0 & 0 & 0 & 0 & 0 \\
Case i & 0 & 0 & 0 & 0 & 0 & 0 & 0 & 0 & 0 & 0 & 0 \\
Case j & 0 & 0 & 0 & 0 & 0 & 0 & 0 & 0 & 0 & 0 & 0 \\
\hline
\end{tabular}

Table 4. The number of people who have a deviation in each wheelchair.

\begin{tabular}{ccc}
\hline & Deviation $(+)$ & Deviation $(-)$ \\
\hline Satndard wheelchair & $11(8,3)$ & $8(2,6)$ \\
Electric wheelchair & $6(3,3)$ & $13(7,6)$ \\
\hline
\end{tabular}

Number (male, female).

\section{Discussion}

This study showed that the pressure of the ischial region shifted during maneuvering of the wheelchair. It is considered that the change in the position of the maximum pressure region during wheelchair driving, which occurred in this 
study, reflects the anterior-posterior movement of the ischium on the seat. This movement of the ischium is thought to be caused by the anterior-posterior tilt of the trunk that occurs during driving and the accompanying anterior-posterior tilt of the pelvis. When the ischium moves on the seat due to the anterior-posterior tilt of the pelvis, a shift occurs between the ischium and the subcutaneous tissue, which is considered to be a risk factor for the development of pressure ulcers. Therefore, we provide guidance on wheelchair prescriptions and contraindications for patients with SCI who have pressure ulcers in the ischial region and patients who require pressure ulcer management in the ischial region by measuring the displacement of the ischial region when driving a wheelchair in a healthy person. Based on this, we compared the changes in the maximum pressure of the ischial region when driving two types of wheelchairs, a self-propelled wheelchair, and an electric wheelchair, and investigated the factors that cause the deviation.

No significant association was found between the wheelchair and ischial region in any of the subjects. In contrast, a significant association was observed in men. Those who were found to have a displacement of the ischial region tended to have pronounced head movements while driving based on the observation results of the video. In addition, because all changes in the maximum pressure region occur anteriorly, the pelvis is considered to tilt backward and the ischium moves anteriorly. However, according to Yang's study [12] at a rate of $0.9 \mathrm{~m} / \mathrm{s}$, there is little activity in the core muscles, and when driving on flat ground, there is almost no activity of the lower limb muscles, and there is no anterior-posterior tilt of the trunk [13]. In this study, the average driving speed of men is $1.01 \pm$ $0.14 \mathrm{~m} / \mathrm{s}$, and women $0.97 \pm 0.17 \mathrm{~m} / \mathrm{s}$, which is equivalent to the result of Yang's study [13], so it is unlikely that muscle contraction caused movement in the pelvis.

The upper limb forms of self-propelled wheelchairs are classified into four types [14], and all of them apply force diagonally forward when driving [15]. A force was applied in the vertical direction and backward from the hand rim according to the law of action and reaction (Figure 2). The ischial region might shift as the upper limbs receive this backward force and the pelvic tilt backward.

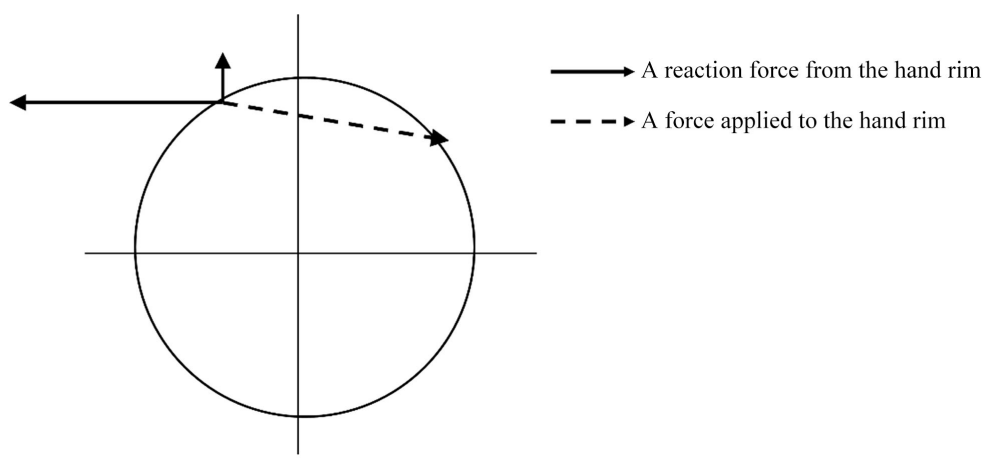

Figure 2. The force applied on the hand rim. A force was applied in the vertical direction and backward from the hand rim during wheelchair maneuvering. 
There was also an example in which a change in the maximum pressure was observed while measuring with an electric wheelchair. The change in the maximum pressure was observed only when the joystick was pushed forward at the start of driving. Because the maximum pressure region did not change during driving, it is possible that when the joystick was pushed forward, the subject's head was bent forward and the trunk was tilted back and forth, causing a shift. Therefore, concerning driving an electric wheelchair on a straight line on flat ground as measured this time, it is unlikely that the ischial region will shift unless the head and trunk are moved when pushing the joystick forward.

The results of this study suggest that the movement of the head and trunk during driving may cause a shift in the ischial region. Therefore, it is desirable to prescribe an electric wheelchair to the patient or instruct the patient to drive with minimal movement of the head and trunk. For patients with SCI who are self-propelled in a wheelchair as a means of transportation, restricted activity due to pressure ulcers in the ischial region leads to a decrease in Quality of Life (QOL) [16]. To improve the QOL of SCI patients, it is desirable to use an electric wheelchair while the pressure ulcer in the ischial region is healing, and to teach them how to drive a self-propelled wheelchair from a preventive point of view after healing.

This study was conducted on flat ground under conditions in which the driving method was restricted. As the driving speed increases, the activity of the trunk muscles and the forward tilt of the trunk also increase [8]; therefore, it is predicted that the displacement of the ischial region will be larger than the result of this study if the driving speed is increased. As described above, it is necessary to assume driving in all situations to spend time in a wheelchair in daily life. By measuring the displacement of the ischial region under various conditions, such as gradient, speed, and activities of daily living, more advanced knowledge can be obtained. Therefore, measurement under different conditions, as described above, is an issue that should be examined in the future.

The FSA sensor mat used this time has a structure in which square sensors with a side of $25.4 \mathrm{~mm}$ are lined up at intervals of $3.1 \mathrm{~mm}$. Because the sitting pressure is displayed only when it is applied to the sensor, the pressure applied between the sensors cannot be measured. Regardless of size, displacement is a risk factor for pressure ulcers; therefore, it is necessary to measure small changes in sitting pressure. However, because of the structure of the sensor mat used this time, it was only possible to measure the deviation in units of at least one square $\left(25.4 \mathrm{~mm}+3.1 \mathrm{~mm}^{2}\right)$. To investigate the displacement of the ischial region in more detail, it is necessary to re-verify it using a device that measures the displacement.

\section{Conclusion}

The ischial region shifted during the maneuvering of both the standard wheelchair and the electric wheelchair. Since it is thought that the movement of the 
spinal column and trunk causes displacement, it is better not to use a self-propelled wheelchair during the period when protection of ischial pressure ulcers is required, such as in the early postoperative period. In addition, it is necessary to provide wheelchair users with guidance on driving methods that reduce the disengagement force.

\section{Ethics}

The purpose of the study was to explain to the subjects, and patient consent was obtained. All procedures were performed according to the principles of the Declaration of Helsinki.

\section{Conflicts of Interest}

The authors declare no conflicts of interest regarding the publication of this paper.

\section{References}

[1] Morita, T., Yamada, T., Watanabe, T. and Nagahori. E. (2015) Lifestyle Risk Factors for Pressure Ulcers in Community-Based Patients with Spinal Cord Injuries in Japan. Spial Cord, 53, 476-481. https://doi.org/10.1038/sc.2015.18

[2] Verschueren, J.H.M., Post, M.W.M., de Groot, S., van der Woude, L.H.V., van Asbeck, F.W.A. and Rol, M. (2011) Occurrence and Predictors of Pressure Ulcers during Primary In-Patient Spinal Cord Injury Rehabilitation. Spial Cord, 49, 106-112. https://doi.org/10.1038/sc.2010.66

[3] Flett H.M., Delparte J.J., Scovil C.Y., Higgins J., Laramee M.T. and Burns A.S. (2019) Determining Pressure Injury Risk on Admission to Inpatient Spinal Cord Injury Rehabilitation: A Comparison of the FIM, Spinal Cord Injury Pressure Ulcer Scale, and Braden Scale. Archives of Physical Medicine and Rehabilitation, 100, 1881-1887. https://doi.org/10.1016/j.apmr.2019.04.004

[4] Ljung, A.C., Stenius, M.C., Bjelak, S. and Lagergren, J.F. (2017) Surgery for Pressure Ulcers in Spinal Cord-Injured Patients following a Structured Treatment Programme: A 10-Year Follow-Up. International Wound Journal, 14, 355-359. https://doi.org/10.1111/iwj.12609

[5] Bates-Jensen, B.M., Guihan, M., Garber, S.L., Chin, A.S. and Burns, S.P. (2009) Characteristics of Recurrent Pressure Ulcers in Veterans with Spinal Cord Injury. The Journal of Spinal Cord Medicine, 32, 34-42. https://doi.org/10.1080/10790268.2009.11760750

[6] Ishikawa, S. and Ichioka, S. (2019) Surgical Treatment of Pressure Ulcers. Japan Society of Pressure Ulcers, 21, 18-23. (In Japanese)

[7] Mendes, P.V.B., Gradim, L.C.C., Silva, N.S., Allegretti, A.L.C., Carrijo, D.C.M. and da Cruz, D.M.C. (2019) Pressure Distribution Analysis in Three Wheelchairs Cushions of Subjects with Spinal Cord Injury. Disability and Rehabilitation: Assistive Technology, 14, 555-560. https://doi.org/10.1080/17483107.2018.1463399

[8] Trewartha, M. and Stiller, K. (2011) Comparison of the Pressure Redistribution Qualities of Two Air-Filled Wheelchair Cushions for People with Spinal Cord Injuries. Australian Occupational Therapy Journal, 58, 287-292. https://doi.org/10.1111/j.1440-1630.2011.00932.x

[9] Kobara, K., Osaka, H., Takahashi, H., Ito, T., Fujita, D. and Watanabe, S. (2015) In- 
fluence of Rotational Axis Height of Back Support on Horizontal Force Applied to Buttocks in a Reclining Wheelchair. Prosthetics and Orthotics International, 39, 397-404. https://doi.org/10.1177/0309364614543547

[10] Park, U.J. and Jang, S.H. (2011) The Influence of Backrest Inclination on Buttock Pressure. Annals of Rehabilitation Medicine, 35, 897-906.

https://doi.org/10.5535/arm.2011.35.6.897

[11] Zemp, R., Rhiner, J., Pluss, S., Togni, R., Plock, J.A. and Taylor, W.R. (2019) Wheelchair Tilt-in-Space and Recline Functions: Influence on Sitting Interface Pressure and Ischial Blood Flow in an Elderly Population. BioMed Research International, 2019, Article ID: 4027976. https://doi.org/10.1155/2019/4027976

[12] Yang, Y.S., Koontz, A.M., Triolo, R.J., Mercer, J.L. and Boninger, M.L. (2006) Surface Electromyography Activity of Trunk Muscles during Wheelchair Propulsion. Clinical Biomechanics, 21, 1032-1041.

https://doi.org/10.1016/j.clinbiomech.2006.07.006

[13] Howarth, S.J., Polgar, J.M., Dickerson, C.R. and Callaghan, J.P. (2010) Trunk Muscle Activity during Wheelchair Ramp Ascent and the Influence of a Geared Wheel on the Demands of Postural Control. Archives of Physical Medicine and Rehabilitation, 91, 436-442. https://doi.org/10.1016/j.apmr.2009.10.016

[14] Boninger, M.L., Souza, A.L., Copper, R.A., Fitzgerald, S.G., Koonts, A.M. and Fay, B.T. (2002) Propulsion Patterns and Pushrim Biomechanics in Manual Wheelchair Propulsion. Archives of Physical Medicine and Rehabilitation, 83, 718-723. https://doi.org/10.1053/apmr.2002.32455

[15] Newsam, C.J., Rao, S.S. and Mulroy, S.J. (1999) Three Dimension Upper Extremity Motion during Manual Wheelchair Propulsion in Men with Different Levels of Spinal Cord Injury. Gait and Posture, 10, 223-232. https://doi.org/10.1016/S0966-6362(99)00034-X

[16] Charlifue, S., Lammertse, D.P. and Adkins, R.H. (2004) Aging with Spinal Cord Injury: Changes in Selected Health Indices and Life Satisfaction. Archives of Physical Medicine and Rehabilitation, 85, 1848-1853. https://doi.org/10.1016/j.apmr.2004.03.017 